\title{
ON THE IMPLICATIONS OF KNOWLEDGE BASES FOR REGIONAL INNOVATION POLICIES IN GERMANY
}

\author{
Robert Hassink, Oliver Plum, Arne Rickmers \\ Department of Geography, Christian Albrechts University in Kiel, Germany
}

Manuscript received: June 6, 2013

Revised version: September 9, 2013

\begin{abstract}
Hassink R., Plum O., Rickmers A., 2014. On the implications of knowledge bases for regional innovation policies in Germany. Quaestiones Geographicae 33(4), Bogucki Wydawnictwo Naukowe, Poznań, pp. 7-16, 5 tables, 1 fig. DOI 10.2478/ quageo-2014-0045, ISSN 0137-477X.

ABSTRACT: Regional innovation policies have been criticised for being too standardised, one-size-fits-all and place-neutral in character. Embedded in these debates, this paper has two aims: first, to analyse whether industries with different knowledge bases in regions in Germany have different needs for regional innovation policies, and secondly, to investigate whether knowledge bases can contribute to the fine-tuning of regional innovation policies in particular and to a modern, tailor-made, place-based regional innovation policy in general. It concludes that although needs differ due to differences in knowledge bases, those bases are useful only to a limited extent in fine-tuning regional innovation policies.
\end{abstract}

KEY WORDS: regional innovation policy, place-based approach, knowledge bases, fine-tuning

Address of the corresponding author: Robert Hassink, Dept. of Geography, Christian Albrechts University in Kiel, HermannRodewald-Str. 9, 24098 Kiel, Germany; e-mail:hassink@geographie.uni-kiel.de

\section{Introduction}

Regional innovation polices have developed strongly both in Germany and large parts of Europe since the mid-1980s. This surge is mainly due to the increasing importance of the regional level with regard to diffusion-oriented innovation support policies (Fritsch, Stephan 2005; Asheim et al. 2003; Nauwelaers, Wintjes 2003; Prange 2008; OECD 2010, 2011; Hassink 1996). Partly supported by national and supranational support programmes and encouraged by strong institutional set-ups found in successful regional economies such as Baden-Württemberg in Germany and Emilia-Romagna in Italy, many regions in Europe have been setting up science parks, technopoles (Hassink, Berg 2014), technological funding schemes, innovation support agencies, community colleges, cluster policies, and initiatives to support the smart specialisation of industries (Enright 2003; McCann, Ortega-Argilés 2011). The central aim of these regional innovation policies is to support regional endogenous potential by encouraging the diffusion of new technologies both from universities and public research establishments to small and medium-sized enterprises (SMEs), between SMEs and large enterprises (vertical co-operation), and between SMEs themselves (horizontal co-operation). Cluster policies are just one part of these broader regional innovation policies, and we often find several cluster initiatives under the roof of one regional innovation policy. The arguments in favour of regionalisation and unfolding endogenous potential in regions have recently been taken up again by scholars supporting a place- 
based approach towards regional development policy (Barca et al. 2012, OECD 2011).

However, complaints have become louder about regional innovation policies being too standardised due to benchmarking and learning from best-practice initiatives (Tödtling, Trippl 2005). Three theoretical concepts can be used to solve this problem: first, emphasising specific barriers in regional innovation systems (Tödtling, Trippl 2005), secondly, analysing the position of clusters in their life cycle (Menzel, Fornahl 2010), and, thirdly, focusing on specific knowledge bases found in industries dominating in the region (Asheim, Gertler 2005).

This paper focuses on the last concept, knowledge bases. It has two aims: first, to analyse whether industries with different knowledge bases in regions in Germany have different needs for regional innovation policies, and secondly, to investigate whether knowledge bases can contribute to the fine-tuning of regional innovation policies in particular and to a modern, tailor-made, place-based regional innovation policy in general. This concept of knowledge bases stresses that industries differ substantially with regard to their specific knowledge base, of which three are distinguished: analytical (science-based), synthetic (engineering-based) and symbolic (creativity-based). The paper presents the research results of three case studies representing these three types of knowledge bases, namely biotechnology in Aachen (analytical), automotive in South-West Saxony (synthetic), and computer game industry in Hamburg (symbolic and synthetic). Detailed results on the knowledge base and network characteristics of these case studies are published elsewhere (Plum 2011; Plum, Hassink 2011, 2013); in this paper we will focus on the policy implications of these results.

In the following section the analytical framework of knowledge bases will be discussed, whereas next sections will present the empirical results and sum up the main conclusions.

\section{Knowledge bases: an analytical framework}

As has been pointed out in the introduction, three theoretical concepts have been developed to tackle the problem of too standardised regional innovation policies. First, by looking at innovation barriers in a typical kind of regions, developed by Tödtling and Trippl (2005). They define three typical deficiencies of regional innovation systems: a low level of clustering and weak endowment with institutions, or organisational thinness, which can be found particularly in peripheral and thinly populated regions, such as parts of Mecklenburg-Vorpommern in Germany; lock-ins and other problems related to over-embeddedness and over-specialisation in old industrial areas, such as the Ruhr area in Germany; and finally, a lack of interaction and networks, or fragmentation, typically found in metropolitan areas, such as Berlin (for suggestions on how to overcome these specific barriers, see Tödtling, Trippl 2005). Secondly, another approach specifically focuses on adapting cluster policies to the position of a cluster in its life cycle (Menzel, Fornahl 2010), which goes from embryonic through emerging and mature to declining stages. At each stage policies should be geared towards the specific demands of the cluster: for instance, they should help companies to focus on a certain technology or standard in the emerging stage, and to widen the thematic boundaries of the cluster in the declining stages.

Although these two approaches have their merits, our empirical research focused on analysing knowledge bases as the third concept, to fine-tune regional innovation policies. According to several authors, industrial knowledge bases represent an essential foundation for getting towards more fine-tuned innovation policies (Asheim, Gertler 2005; Asheim et al. 2011; Martin et al. 2011). Martin et al. (2011: 555) explicitly argue that the differentiated knowledge-base concept "through clarifying different preconditions for innovation in different industries, can serve as a heuristic model for designing fine-tuned regional innovation policy“.

A knowledge base refers to the area of knowledge itself as well as to its embodiment in tech- 
Table 1. Knowledge bases.

\begin{tabular}{|c|c|c|c|}
\hline Criteria & Analytical & Synthetic & Symbolic \\
\hline Main rationale & Science based & Engineering based & Creativity based \\
\hline Nature of knowledge & $\begin{array}{l}\text { Codified (documentation in } \\
\text { patents and publications) }\end{array}$ & $\begin{array}{l}\text { Tacit (concrete know-how, } \\
\text { craft and practical skills) }\end{array}$ & $\begin{array}{l}\text { Tacit (concrete know-how, } \\
\text { craft, practical and search } \\
\text { skills) }\end{array}$ \\
\hline $\begin{array}{l}\text { Process of knowledge } \\
\text { creation }\end{array}$ & $\begin{array}{l}\text { Deductive process, formal } \\
\text { models, know-why }\end{array}$ & $\begin{array}{l}\text { Inductive process, applied, } \\
\text { problem related, know-how }\end{array}$ & $\begin{array}{c}\text { Interactive, informal, } \\
\text { creative, problem oriented, } \\
\text { know-how }\end{array}$ \\
\hline Type of innovation & $\begin{array}{l}\text { Radical innovation by crea- } \\
\text { tion of new knowledge }\end{array}$ & $\begin{array}{l}\text { Incremental innovation by } \\
\text { application and by combina- } \\
\text { tion of existing knowledge }\end{array}$ & $\begin{array}{l}\text { Innovation by creative } \\
\text { recombination of existing } \\
\text { knowledge and by creation } \\
\text { of new ideas and images }\end{array}$ \\
\hline $\begin{array}{l}\text { Mode of knowledge } \\
\text { networking }\end{array}$ & $\begin{array}{c}\text { Research collaboration } \\
\text { between firms (R\&D } \\
\text { departments) and research } \\
\text { organisations }\end{array}$ & $\begin{array}{l}\text { Interactive learning with } \\
\text { customers and suppliers }\end{array}$ & $\begin{array}{l}\text { Interaction in professional } \\
\text { communities, learning from } \\
\text { youth/street/'fine' culture }\end{array}$ \\
\hline $\begin{array}{l}\text { Importance of spatial } \\
\text { proximity }\end{array}$ & Low to medium & Medium to high & Medium to high \\
\hline
\end{tabular}

Source: own modification of Asheim, Gertler (2005), Asheim (2007), and Asheim et al. (2011).

niques and organisations (Asheim, Gertler 2005). We can distinguish between three types of knowledge base: analytical, synthetic and symbolic (Table 1).

\section{Analytical knowledge base}

Rooted in the Aristotelian epistèmè notion, the analytical knowledge base refers particularly to universal and theoretical knowledge in order to understand and explain features of the (natural) world (science-based/ know-why). Innovation processes within industrial settings that draw on this knowledge base are strongly dependent on scientific knowledge input. Knowledge creation is often based on deductive cognitive and rational processes, or on formal models that require abstraction skills. Examples are laboratory-based research or scientific discourses. Basic and applied research as well as systematic product and process development both belong to the core activities of firms. In order to turn knowledge successfully into innovation, firms often have their own R\&D departments, but also heavily rely on research results of universities and other research organisations. Therefore, university-industry links and scientific networks in the context of epistemic communities are common in industries dominated by the analytical knowledge base. The strong influence coming from the scientific base is also reflected in high academic spin-off activities, a formal organisation of $R \& D$ in de- partments, and a high share of codified knowledge through reports, electronic files or patent descriptions. Since knowledge is often codified, it is easier to exchange between globally distributed actors (Asheim et al. 2011). The core of the workforce needs university education and/or research experience. The application of knowledge in such industries is often integrated in more radical product or process innovations.

\section{Synthetic knowledge base}

The synthetic knowledge base derives from the Aristotelian technè notion. Hence, it refers more to knowledge that is instrumental, context-specific and practice-related for the purpose of designing or constructing something to attain functional goals (engineering-based/ know-how). Product and process innovation takes place mainly via the application or a (new) combination of existing knowledge in order to solve a specific problem that appears in interaction with clients and suppliers. Knowledge formation is characterised as a more inductive process. Characteristic activities are, for example, system design, prototyping, fine tuning, testing, and practical work in general. $R \& D$ intensity is generally lower than in the first type. The stress within R\&D tends to be on the D part in the form of product or process development. If research is a matter of interest, it is mainly applied research, even within industry-university relationships. Interactive learning 
Table 2. Overview of firm interviews.

\begin{tabular}{|l|c|c|c|c|}
\hline & $\begin{array}{c}\text { Case I - biotech in } \\
\text { Aachen }\end{array}$ & $\begin{array}{c}\text { Case II - automotive in } \\
\text { South-West Saxony }\end{array}$ & $\begin{array}{c}\text { Case III - video game de- } \\
\text { velopment in Hamburg }\end{array}$ & Cases I - III \\
\hline Period & $06 / 08-01 / 09$ & $03 / 09-10 / 09$ & $05 / 10-10 / 10$ & $06 / 08-10 / 10$ \\
\hline Population & 27 & 112 & 25 & $\Sigma 164$ \\
\hline No. of firms interviewed & 23 & 58 & 20 & $\Sigma 101$ \\
\hline Response rate & $85 \%$ & $52 \%$ & $80 \%$ & $\varnothing 72 \%$ \\
\hline
\end{tabular}

is often dominated by industry-industry links, and frequently shows features of communities of practice. Due to the fact that knowledge often arises from experience gained at a workplace, and via learning by doing or using and interacting, tacit knowledge is typically more important here than in the analytical knowledge base. The strong tacit nature of knowledge almost always requires being at the same time at the same place in order to share this knowledge. As a result, the synthetic type shows a relatively stronger sensitivity to spatial proximity between innovation partners. Professional and polytechnic schools are of particular importance as well as on-the-job training to provide an adequate educational background facilitating concrete know-how, crafts and practical skills. Innovation processes in such industries have mainly an incremental nature. They usually take place in already existing firms, whereas spin-offs are relatively less frequent (Asheim et al. 2011).

\section{Symbolic knowledge base}

Creative and cultural industries, such as film making, music, design, fashion, publishing, or advertising (Berg, Hassink 2013), are good examples of economic sectors for which symbolic knowledge inputs are of fundamental importance. As can be seen in Table 1, some of the key features of the symbolic knowledge base are similar to those of the synthetic one. By contrast, analogies with the analytical knowledge base are rather slight. The main argument for distinguishing between the symbolic and the synthetic knowledge base can be found in the tangibility of the end-products of the respective innovation processes. Industrial activities which rely on the symbolic knowledge base particularly target the intangible, aesthetic attributes of a product, the creation of designs and images, as well as the economic use of various forms of cultural artifacts. "Knowledge is therefore incorporated and transmitted in aesthetic symbols, images, (de) signs, artifacts, sounds and narratives. This type of knowledge is strongly linked to a deep understanding of the habits and norms and 'everyday culture' of specific social groups, and is, therefore, characterised by a strong tacit component" (Asheim 2007: 226). Since the development of new products or processes is particularly based on creativity, an aesthetic sense, imagination, interpretative and artistic skills rather than on cognitive information processing or the application of scientific rules, formal qualifications and university degrees are usually relatively unimportant for recruitment decisions (Martin, Moodysson 2013). Considering that predominantly tacit capabilities are hard to transfer from one individual to another, the know-who of po-

Table 3. Overview of expert interviews.

\begin{tabular}{|l|c|c|c|c|}
\hline & $\begin{array}{c}\text { Case I - biotech in } \\
\text { Aachen }\end{array}$ & $\begin{array}{c}\text { Case II - automotive in } \\
\text { South-West Saxony }\end{array}$ & $\begin{array}{c}\text { Case III - video game de- } \\
\text { velopment in Hamburg }\end{array}$ & Cases I - III \\
\hline Period & $01 / 09$ & $03 / 10$ & $01 / 11-02 / 11$ & $01 / 09-02 / 11$ \\
\hline $\begin{array}{l}\text { Cluster managers and } \\
\text { network coordinators }\end{array}$ & 4 & 3 & 4 & $\Sigma 11$ \\
\hline $\begin{array}{l}\text { Representatives of state } \\
\text { ministries }\end{array}$ & 1 & 1 & - & $\Sigma 2$ \\
\hline $\begin{array}{l}\text { Representatives of public } \\
\text { research/ educational } \\
\text { organisations }\end{array}$ & 2 & 1 & 1 & $\Sigma 4$ \\
\hline Academic experts & 2 & 3 & 2 & $\Sigma 7$ \\
\hline $\begin{array}{l}\text { Total number of experts } \\
\text { interviewed }\end{array}$ & 9 & 8 & 7 & $\Sigma 24$ \\
\hline
\end{tabular}


tential collaborators working in the given professional community defines a crucial strategy for combining complementary talents within temporary project settings in a fruitful arrangement. The importance of buzz and face-to-face-contacts leads to relatively high sensitivity to the spatial proximity of potential project partners. Urban environments rather than sparsely populated spaces provide an appropriate setting for inspiration and acquaintance for people who make the difference in creativity-driven innovation processes.

\section{Empirical findings}

As written in the introduction, detailed results of the research on network patterns found in the clusters have been published elsewhere (Plum 2011; Plum, Hassink 2011, 2013). After introducing the cases in the following section, what we will do in the next is to present the hitherto unpublished policy findings of our research in order to shed light on differences in policy needs between industries with different knowledge bases. The research was based on both, interviews in a total of 101 firms (Table 2) and 24 expert interviews in the three case regions (Table 3), conducted between 2008 and 2011.

\section{Introducing the case regions}

The biotech cluster is located in the former old industrial Aachen Technology Region (TR), which lies in the westernmost part of the State of North Rhine-Westphalia and borders on Belgium and the Netherlands (for more details, see Plum, Hassink 2011). Its population is about 1.3 million living in five counties (Kreise) and the major city, Aachen $(240,000)$. In the past few decades, the region underwent intense restructuring processes. Supported by a strong research/ educational infrastructure and restructuring policies, lock-ins hampering the exploration of new economic development paths seem to have been overcome. Today, the regional economy is in the process of developing competences in a couple of high-tech industries. The biotechnology industry is one of those industries that profit from the spatial proximity to world-renowned research and educational facilities. The Aachen Technology
Region is part of the BioRegio Rhineland, one of the three German key biotechnology regions that have won the BioRegio contest organised by the Federal Ministry of Education, Science, Research and Technology (BMBF). Almost half of the interviewed firms are spin-offs from organisations of the regional knowledge generation subsystem. Most of them spun off from institutes of the RWTH Aachen University, one of the 11 German 'universities of excellence'. This university in particular is well known for its competence in a wide range of engineering and natural sciences. Other important research institutes are the University Hospital Aachen, the Fraunhofer Institute for Molecular Biology and Applied Ecology (IME) in Aachen, and the Jülich Research Centre (FZJ), a member of the Helmholtz Association, one of the largest research centres in Europe. LifeTecAachen-Jülich e.V. is the central cluster initiative for life-science activities in the Aachen TR. It aims at establishing networks between relevant stakeholders from science, industry, development agencies and capital involved in and giving support to innovation processes in life sciences, with particular focus on biotechnology and medical engineering. Our main empirical outcome was that the analytical knowledge base was crucial for innovation activities in biotechnology industry in the Aachen Technology Region (Plum, Hassink 2011). The interactive learning of biotechnology firms within the region is clearly dominated by industry-university links, while for most firms the vertical dimension of co-operative innovation processes tends to be shaped at the national and global scales.

The automotive industry is located in SouthWest Saxony (SWS), which lies in the south-western part of the Free State of Saxony and borders on the federal states of Thuringia and Bavaria in the west and the Czech Republic in the south (after Plum, Hassink 2013). The population of SWS is about 1.6 million and stretches across four counties and the major city, Chemnitz $(244,000)$. Since the region was part of the former German Democratic Republic, its economic system had to undergo an extensive transformation after the collapse of communism in 1989. In 2009, the unemployment rate in SWS (13\%) was still considerably higher than the German average $(8 \%)$. The region is strongly shaped by its manufacturing 
activities: whereas its employment share in the manufacturing sector was $27 \%$ in 2009, the corresponding value for Germany was $19 \%$. SWS has a rich history of producing cars and is still the unchallenged centre of automotive manufacturing in eastern Germany. The 58 automotive firms interviewed profit not only by the spatial proximity to adjacent OEMs (Volkswagen in Mosel, Chemnitz and Dresden, as well as BMW and Porsche in Leipzig); they also benefit from specialised research and educational facilities nearby. Besides, there are a number of organisations in SWS which build up a fairly thick supportive infrastructure targeting the competitiveness of the regional economy. The Saxony automotive supplier network AMZ is the central cluster initiative that promotes networking between automotive suppliers along the value chain. Parallel network initiatives are run by Volkswagen Sachsen $\mathrm{GmbH}$ and the Automotive Cluster Ostdeutschland ACOD. Other institutions that target the regional industry's development, though without a special focus on the automotive industry, are the regional Chamber of Industry and Commerce in Chemnitz as well as the Saxony's Economic Development Agency in Dresden. The empirical outcome of our research has revealed that the regional industry heavily relies on the synthetic knowledge base (Plum, Hassink 2013), whereas the analytical knowledge base is comparatively weak. The firms' low performance in the analytical mode of knowledge creation holds the risk of them losing the capacity to come up with highly innovative technical solutions in the future.

The analysed video game industry is located in Hamburg, the second largest city in Germany (1.8 million inhabitants) (for a detailed description of this case, see Plum 2011). Beside the comparatively high employment share of port-related services, a glance at Hamburg's overall labour market structure reveals a high percentage of the tertiary sector in general, which is clearly above the national average. Here the relatively high share of jobs in business-related services stands out most strikingly. Creative industries make up around $7 \%$ of Hamburg's total employment rate. The city is one of Germany's most important hot spots of the media sector, with particularly high concentrations in publishing and advertisement.
There is also a well-established IT sector, so the accumulated expertise of both, media and IT, provides a potentially fertile basis for the evolution of the interactive game industry. In fact, Hamburg's video game sector is, so far, relatively small in terms of labour shares and business volume compared with the overall media and IT sectors in this city. Nevertheless, in recent years its fast growth made Hamburg one of the leading centres for video game development (VGD) and publishing in Germany. The supportive infrastructure targeting the competitiveness of the video game industry in Hamburg mirrors the typical hierarchical structure of Germany's federalist institutional support system: at the national level, the G.A.M.E. Bundesverband der Entwickler von Computerspielen e.V. aims at boosting the German VGD industry as a whole, whereas at the local/regional level, the VGD firms make use of support activities offered by the cluster initiative gamecity: Hamburg. From an educational point of view, attempts have been undertaken to professionalise and formalise the academic education in VGD at the HAW Hamburg University of Applied Sciences, which offers a master's degree program Games. The focus is on training students in practical skills rather than teaching them scientific rules. In addition, the gamecity: Lab Hamburg, co-founded by two departments of the HAW, and gamecity: Hamburg aim at facilitating knowledge and technology transfers between industry and academia. This case challenged the assumption that learning, knowledge, and innovation processes within creative industries were predominantly shaped by the symbolic knowledge base (Asheim et al. 2011). The central finding of our empirical research was that this was not entirely true. According to our analysis, both symbolic and synthetic knowledge, and to a lesser extent analytical knowledge, are the dominant elements that contribute to video game development in Hamburg.

The qualitative illustration of the core outcomes in Figure 1 clearly demonstrates that analysing industrial knowledge bases does not mean thinking in defined categories, but in a continuum of configurations of the various knowledge base concept. As such, this finding apparently supports Asheim et al. (2011), who propose that most economic activities in the real world are 


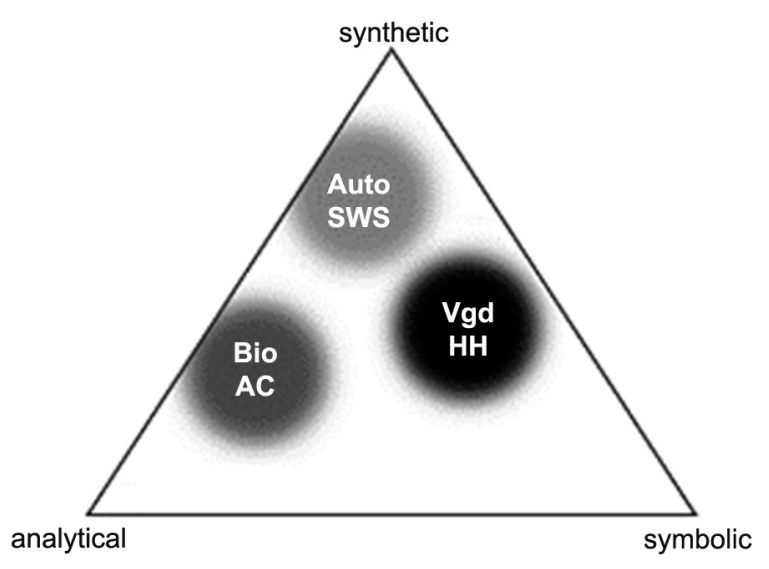

Fig. 1. Positioning of regional industries within the knowledge base concept triangle.

Source: Plum (2011: 181); inspired by Asheim (2007: 227).

driven by more than just one knowledge base, though the degree to which a particular knowledge base is dominant varies between industries.

\section{Policy-related findings}

From a policy perspective, our empirical analysis focused on two aspects of innovation support: first, problems of the current funding environment, or why subsidy offers are not perceived, and secondly, how the funding environment could be improved. The empirical results concerning these questions will first be described separately. Finally this chapter will show common features and differences between the clusters. The results presented are based on quantitative data of the questionnaire and qualitative statements collected in the interviews.

In the biotechnology industry in the Aachen Technology Region (case 1) the main problems of the affected firms were lack of time $(60.9 \%$ of all firms) and a too complicated funding structure $(52.2 \%)$ (see Table 4). In open questions a lot of firms pointed out that the funding support is too complex and bureaucratic, especially for SMEs. Some firms, however, did not make use of funding initiatives because they wanted to stay independent and to avoid knowledge drain through funded networks. The interviewees emphasised that for many years there was no support in getting access to global pipelines of knowledge flows, but that recently support in this area has improved greatly. Also market-oriented support used to be neglected, but has improved much.
Table 4. Problems that caused non-funding in different industries.

\begin{tabular}{|l|c|c|c|c|}
\hline & $\begin{array}{c}\text { Biotech } \\
(\mathrm{n}=23)\end{array}$ & $\begin{array}{c}\text { Auto- } \\
\text { motive } \\
(\mathrm{n}=58)\end{array}$ & $\begin{array}{c}\text { Video } \\
\text { games } \\
(\mathrm{n}=20)\end{array}$ & $\begin{array}{c}\text { Total } \\
(\mathrm{n}=101)\end{array}$ \\
\hline $\begin{array}{l}\text { Project was } \\
\text { turned down (\%) }\end{array}$ & 39.1 & 19.0 & 10.0 & 22.0 \\
\hline $\begin{array}{l}\text { Lack of } \\
\text { information (\%) }\end{array}$ & 30.4 & 24.1 & 35.0 & 28.0 \\
\hline $\begin{array}{l}\text { Too complicated } \\
(\%)\end{array}$ & 52.2 & 72.4 & 70.0 & 68.0 \\
\hline Lack of time (\%) & 60.9 & 41.4 & 55.0 & 49.0 \\
\hline $\begin{array}{l}\text { No fitting } \\
\text { instruments (\%) }\end{array}$ & 47.8 & 36.2 & 50.0 & 42.0 \\
\hline Other (\%) & & 81.0 & 65.0 & \\
\hline
\end{tabular}

Source: own survey.

The interviews also pointed out that there was still the problem of complexity for SMEs.

The investigated biotech firms mostly wanted additional support in finding business partners and concerning the provision of financial aid (both $43.5 \%$; see Table 5). The latter is mostly seen as key support in the start-up phase. Another basic result is the striking demand of particularly SMEs for consultancy of different support options. The interviewees pointed out that a simplification of the application process could help to raise the share of supported SMEs. The programmes should not stick too much to administrative areas such as Länder, but be more flexible from a geographical-administrative point of view. A long-term, complementary support structure rather than a redundant, ad-hoc one could simplify the funding environment. Finally, a fundamental outcome of many interviews is the need to have one strong external representation

Table 5. Policy support demanded by firms in different industries.

\begin{tabular}{|l|c|c|c|c|}
\hline & $\begin{array}{c}\text { Biotech } \\
(\mathrm{n}=23)\end{array}$ & $\begin{array}{c}\text { Auto- } \\
\text { motive } \\
(\mathrm{n}=58)\end{array}$ & $\begin{array}{c}\text { Video } \\
\text { games } \\
(\mathrm{n}=20)\end{array}$ & $\begin{array}{c}\text { Total } \\
(\mathrm{n}=101)\end{array}$ \\
\hline Financing (\%) & 43.5 & 39.7 & 45.0 & 42.0 \\
\hline Staff training (\%) & 39.1 & 51.7 & 35.0 & 46.0 \\
\hline $\begin{array}{l}\text { Information about } \\
\text { market (\%) }\end{array}$ & 34.8 & 27.6 & 45.0 & 33.0 \\
\hline $\begin{array}{l}\text { Information about } \\
\text { technology (\%) }\end{array}$ & 21.7 & 27.6 & 15.0 & 24.0 \\
\hline Consultancy (\%) & 26.1 & 13.8 & 25.0 & 19.0 \\
\hline $\begin{array}{l}\text { Finding partners } \\
(\%)\end{array}$ & 43.5 & 20.7 & 20.0 & 26.0 \\
\hline Other (\%) & & 53.4 & 60.0 & \\
\hline
\end{tabular}

Source: own survey. 
of the region at fairs etc., so that it can channel the interests of its firms with one voice.

With regard to the automotive industry in South-West Saxony (case 2), the firms primarily have the problem of a too complicated funding environment (72.4\%) (Table 4). Particularly SMEs are rarely capable of coping with the bureaucratic requirements due to lack of time, which was confirmed in expert interviews. The problem of large enterprises is that many applications for projects are turned down because support is mainly intended for SMEs. A specific problem occurs for SMEs owned by a parent company. They are often not eligible for funding. Furthermore, both firms and experts criticised the lack of a coherent strategy at the regional level aiming at the specialisation of skills and knowledge. There is not enough cross-linking between universities or polytechnics and firms in that respect. SMEs often do not have access to global pipelines and are often dependent on the knowledge transfer connections of OEMs.

Firms of the automotive industry mostly demand support for training initiatives for employees $(51.7 \%)$ (Table 5). A more detailed view shows that especially small firms and firms that were established after 1990 (reunification) need more policy support than larger and older firms. While larger firms want training initiatives, SMEs also seek financial support and technology information. Almost all firms want a simplification of the support and more tailor-made information. Some firms claim that policy should strengthen their efforts to keep educated and skilled workforce in the region. This can be regarded as a region-specific problem rather than a knowledge-base driven one. Furthermore, SMEs expressed the need for pooling their interests in order to strengthen their market position as well as getting access to external knowledge flows. The interviewed policy experts were in favour of a demand-based, incremental innovation policy. They suggested, e.g., strengthening networks of alumni, more start-up-oriented support or seeking for partner regions, and gaps in the supply chain that could be closed.

Concerning the video game industry in Hamburg (case 3), the crucial problem for most of the firms (as in the above cases) is the complicated funding structure $(70 \%$; Table 4$)$. It was pointed out that bureaucratic processes hinder application funding. Some of those firms also criticised the focus of support being on technological innovations rather than on contents or final effects. The interviewed experts stress that due to their small size the firms' orientation to international markets and also global labour sourcing is difficult. Even worse, these firms suffer a brain drain of the labour force to large foreign enterprises. Another problem concerning labour skills is the shortage of arts graduates from German universities. For the case of knowledge generating in the video game industry, universities often even cannot keep up with firms.

The biggest demand of firms in the case of the video game industry is related to market information and financial support (both $45.0 \%$; Table 5). In open questions some larger enterprises pointed out that alumni should have more practical experience. Others wish for tax concessions like those observed in Canada. Policy should also treat video games as an object of cultural value. That means a provision of a framework for a fair debate which also takes the benefits of gaming into account. The expert interviewees pointed out that policy should primarily provide contact possibilities to generate buzz in the form of conferences or contact forums, particularly in order to find freelancers for projects. Other suggestions are bringing programmers and designers together at an early stage (e.g. in university projects) and establishing incentives like awards to generate professionalisation and entrepreneurial skills.

Besides the common complaints concerning the complexity and bureaucracy of the funding structure as the primary hindrance of support efficiency in all three cases, particularly for SMEs, as well as the common demand for pooling interests for a better market position, there are also some interesting policy-related differences between the industries and their underlying knowledge bases. As to the occurring problems, the values for case 2 are on average marginally below those for the other cases. In case 1 a relatively high number of support applications were turned down, which might have been caused by insufficient consultancy at the pre-application stage. Another interesting result that distinguishes case 1 from the others is the relatively high number of firms that are not interested in knowl- 
edge transfer because of knowledge drain effects. Other specific problems, such as the bad image in case 3 and brain drain in case 2, seem to be mostly influenced by the characteristics of the national (case 3) and regional (case 2) contexts rather than driven by the industry or knowledge base.

The demand of support also partly differs between the cases. The biggest need occurs in case 1 , more precisely the need for support in finding partners, which is much bigger than in the other cases. Case 2, in turn, is dominated by a significant need for employee training initiatives. Market information is quite important for case 3 , and to a lesser extent also for case 1 . However, both cases do not pay much attention to technology support: in case 1 a lot of firms want to act independently in creating knowledge, and in case 3 it is rather lack of reliance on the innovativeness of governmental institutions. Since the needs differ a lot between different suppliers of case 2 , the size- and maturity structure is another important attribute for a well-developed funding environment. This shows that in general innovation policies are quite difficult to steer on the basis of industries or knowledge bases.

\section{Discussion and conclusions}

The starting point of this paper was the concept of knowledge bases and its implications for regional innovation policies. This concept stresses that industries differ substantially with regard to their specific knowledge base, of which three are distinguished: analytical (science-based), synthetic (engineering-based) and symbolic (creativity-based). On the basis of the results of three case studies in Germany representing these three types of knowledge bases, namely biotechnology in Aachen (analytical), automotive in SouthWest Saxony (synthetic), and the computer game industry in Hamburg (symbolic), we can conclude that there are differences among industries with different knowledge bases concerning the character of networks, innovation patterns, and knowledge exchange partners (as shown in previous publications, see Plum 2011; Plum, Hassink 2011, 2013), but also with regard to the needs for innovation policy (as shown in this paper). It is questionable, however, to what extent these differences can only be explained by differences in knowledge bases. They are also caused by specific regional context-related factors, such as out-migration, the history and ownership of firms, the location of universities and research institutes, etc.

The second aim of the paper was to analyse whether knowledge bases could serve to solve the problem of too standardised, one-size-fitsall regional innovation policies (Tödtling, Trippl 2005; Barca et al. 2012), as was claimed by Martin et al. (2011) on the basis of an empirical study of Scania in Sweden. On the basis of our empirical findings, we can conclude that although knowledge bases are potentially useful in fine-tuning cluster policies, they are much less so in fine-tuning broader regional innovation policies for several reasons. First, as has been stated above, the policy needs found among firms from different industries in regions are only partly related to the knowledge base of the given industry. Factors related to the specific regional context also play a role in explaining differences in policy needs. Secondly, one hardly finds mono-structural regional economies in which one industry, and hence one knowledge base, fully dominates, which means that in most regions knowledge about several industries with different knowledge bases is necessary among regional policy-makers and innovation support agencies to fine-tune regional innovation policies, which is far from realistic. Thirdly, since knowledge bases are not static and set in stone, policies need to pay attention to the dynamics of knowledge bases in a regional context and also to the potential convergence tendencies between the bases that can take place, which is also a highly complex task that goes beyond the capacities of policy-makers. All in all, the knowledge base concept seems to be useful in fine-tuning policy at the cluster level, but much less so at the regional level. Alternatively, geographical attributes in relation to innovation barriers which are more place-based in character, as proposed by Tödtling and Trippl (2005), seem to be more useful for fine-tuning regional innovation policies.

We are hence more sceptical than Martin et al. (2011) when it comes to the role of knowledge bases as a concept for fine-tuning regional innovation policies. Others, such as Manniche (2012), 
Tödtling et al. (2011), and Asheim et al. (2011), see knowledge bases as a starting point to look for bridges between industries and clusters in order to foster related variety, platforms of innovation, and more integrative regional innovation policies. Although we endorse their main thrust in looking for new combinations, we are not sure whether studying knowledge bases is really necessary to realise such a regional innovation policy. A careful research on clusters and their knowledge networks and innovation characteristics in a region should suffice to find out whether there are potentials for related variety, platforms of innovation, or cross-clustering.

\section{Acknowledgements}

This research was sponsored by the European Science Foundation and the Research Council of Norway. The usual disclaimer applies.

\section{References}

Asheim B.T., 2007. Differentiated knowledge bases and varieties of regional innovation systems. Innovation: The European Journal of Social Sciences Research 20: 223-241.

Asheim B.T., Boschma R., Cooke P., 2011. Constructing regional advantage: Platform policies based on related variety and differentiated knowledge bases. Regional Studies 45 (7): 893-904.

Asheim B.T., Gertler M.S., 2005. The geography of innovation: Regional innovation systems. In: Fagerberg J., Mowery D., Nelson R. (eds), The Oxford Handbook of Innovation. Oxford University Press, Oxford: 291-317.

Asheim B.T., Isaksen A., Nauwelaers C., Tödtling F. (eds), 2003. Regional innovation policy for small-medium enterprises. Edward Elgar, Cheltenham.

Barca F., McCann P., Rodríguez-Pose A., 2012. The case for regional development intervention: Place-based versus place-neutral approaches. Journal of Regional Science 52: 134-152.

Berg S.-H., Hassink R., 2013. Creative industries from an evolutionary perspective: A critical literature review. Papers in Evolutionary Economic Geography, 13.06. Utrecht.

Enright M., 2003. Regional clusters: What we know and what we should know. In: Bröcker J., Dohse D., Soltwedel R. (eds), Innovation clusters and interregional competition. Springer, Berlin: 99-129.
Fritsch M., Stephan A., 2005. Regionalization of innovation policy - Introduction to the special issue. Research Policy 34: 1123-1127.

Hassink R., 1996. Technology transfer agencies and regional economic development. European Planning Studies 4(2): 167-184.

Hassink R., Berg S.-H., 2014. Regional innovation support systems and technopoles. In: Oh D.S., Phillips F.Y. (eds), Technopolis: Best practices for science $\mathcal{E}$ technology cities. Springer, Heidelberg (forthcoming).

Manniche J., 2012. Combinatorial knowledge dynamics: On the usefulness of the differentiated knowledge base model. European Planning Studies 20: 1823-1841.

Martin R., Moodysson J., 2013. Comparing knowledge bases: On the geography and organization of knowledge sourcing in the regional innovation system of Scania, Sweden. European Urban and Regional Studies 20: 170-187.

Martin R., Moodysson J., Zukauskaite E., 2011. Regional innovation policy beyond 'best practice': Lessons from Sweden. Journal of the Knowledge Economy 2: 550-568.

McCann P., Ortega-Argilés R., 2011. Smart specialisation, regional growth and applications to EU cohesion policy. IEB Working Papers, 2011/14, University of Barcelona.

Menzel M.-P., Fornahl D., 2010. Cluster life cycles - dimensions and rationales of cluster evolution. Industrial Corporate Change 19(1): 205-238.

Nauwelaers C., Wintjes R., 2003. Towards a new paradigm for innovation policy? In: Asheim B., Isaksen A., Nauwelaers C., Tödtling F. (eds), Regional innovation policy for small-medium enterprises. Edward Elgar, Cheltenham: 193-220.

OECD, 2010. Regional development policies in OECD countries. OECD, Paris.

OECD, 2011. Regions and innovation policy. OECD reviews of regional innovation. OECD, Paris.

Plum, O., 2011. Developing biotech products, making cars, creating video games: Disentangling knowledge bases in three German regions. Doctoral dissertation, University of Kiel.

Plum O., Hassink R., 2011. On the nature and geography of innovation and interactive learning: A case study of the biotechnology industry in the Aachen Technology Region, Germany. European Planning Studies 19: 1141-1163.

Plum O., Hassink R., 2013. Analytical vs. synthetic knowledge: Which knowledge base configuration drives Southwest Saxony's automotive firms? European Urban and Regional Studies 20: 206-226.

Prange H., 2008. Explaining varieties of regional innovation policies in Europe. European Urban and Regional Studies 15: 39-52.

Tödtling F., Schneider R., Grillitsch M., Höglinger C., 2011. Constructing regional advantage in the Austrian ICT sector - Towards fine-tuned innovation policies? Journal of the Knowledge Economy 2: 533-549.

Tödtling F., Trippl M., 2005. One size fits all? Towards a differentiated regional innovation policy. Research Policy 34(1): 203-1219. 